\title{
Morphological Features of Foreign Body Giant Cells in Experimental Conditions
}

\author{
Mariya A. Zatolokina ${ }^{1 *}$; Ekaterina S. Mishina ${ }^{1}$; Alexander A. Sozykin ${ }^{2}$; \\ Marina V. Gorbunova ${ }^{3}$; Alexander G. Alekseev ${ }^{3}$ \\ ${ }^{1}$ Kursk State Medical University, Kursk, Russia \\ ${ }^{2}$ Rostov State Medical University, Rostov-on-Don, Russia \\ ${ }^{3}$ Medical Institute, Orel State University named after I.S. Turgenev, Orel, Russia
}

\begin{abstract}
Background: The purpose of our work was determined by the accumulation of a significant amount of experimental material under the conditions of implantation of a foreign body, a mesh implant, into the region of the anterior abdominal wall in order to obtain experimental inflammation, in which foreign body giant cells (FBGCs) were constantly visualized as reactive formations. This research aimed to study the dynamics of morphological changes in FBGCs under conditions of experimental implantation of a foreign body, a mesh implant, and the possible mechanism of their formation

Methods and Results: This study was carried out on male Wistar rats, in which a foreign body was implanted — a mesh endoprosthesis made of polypropylene - in the region of the anterior abdominal wall under the aponeurosis of the rectus abdominis muscles. A section of the anterior abdominal wall with the implanted endoprosthesis was excised on Days 10, 21, 30, and 60 after surgery, fixed in $10 \%$ buffered formalin solution. The obtained samples were embedded in paraffin according to standard prescriptions; histological sections with a thickness of 5-7 $\mu \mathrm{m}$ were made and stained with $\mathrm{H} \& \mathrm{E}$, according to the methods of Van Gieson and Mallory, and an immunohistochemical study was performed using the marker of cell proliferation (Ki-67). The revealed structural features of multinucleated cells were recorded by microphotography using a photo attachment and a Levenhuk video camera (USA).

During the study, it was revealed that the amount, functional activity and morphological diversity of FBGCs gradually increased, reaching a maximum by Day 30 of the experiment. At a later date, some of them died, while the remaining part was differentiated, splitting into small multinucleated cells and mononuclear elements, morphologically identical to macrophages and fibroblasts. The formation of FBGCs continued as long as the mesh implant was in the body.
\end{abstract}

Conclusion: FBGCs are reactive formations that arise in response to various endo- and exogenous irritation.(International Journal of Biomedicine. 2021;11(2):212-215.)

Key Words: foreign body giant cells $\bullet$ multinucleated giant cells $\bullet$ endoprosthetics $\bullet$ reactivity $\bullet$ phagocytosis

For citation: Zatolokina MA, Mishina ES, Sozykin AA, Gorbunova MV, Alekseev AG. Morphological Features of Foreign Body Giant Cells in Experimental Conditions. International Journal of Biomedicine. 2021;11(2):212-215. doi:10.21103/Article11(2)_ OA15

\section{Introduction}

Multinucleated elements include striated muscle fibers, mesenchymal tissue at a certain stage of its development, and multinucleated cells that appear as reactive formations

*Corresponding author: Prof. Mariya A. Zatolokina, PhD, ScD. Department of Histology, Embryology, and Cytology. Kursk State Medical University. Kursk, Russia.E-mail: marika1212@mail.ru in reticular, connective, and epithelial tissues. The nonnomenclature designation of multinucleated cells is extremely diverse, in particular, osteoclasts (multinucleated cells of bone tissue), as well as foreign body giant cells (FBGCs) and Langhans cells, which can be found in connective tissue in inflammation. ${ }^{(1-}$ ${ }^{3)}$ I.I. Mechnikov first noticed the role of the FBGCs: In 1883, I.I. Mechnikov experimentally confirmed the phagocytic function of FBGCs, and also believed that FBGCs appear as reactive formations in inflammation of various etiologies. ${ }^{(4)}$ 
Currently, the majority of domestic and foreign authors are of the opinion that FBGCs are physiological elements of the connective tissue system, and their number, size, and degree of phagocytic activity serve as criteria for determining the degree of connective tissue reactivity.

At the beginning of the last century, A. Nemilov (1937) wrote that the morphogenesis of FBGCs has a special biological significance, manifested by the general ability of a multicellular organism to respond to changes in environmental conditions by changing the degree of dissection of the multinucleated giant cells (MNGCs). Considering the fact that FBGCs occur in some organs with certain functional rearrangements, under conditions of various experimental influences during regenerative processes and are reactive formations with the function of phagocytosis, it seems appropriate to dwell in more detail on the methods of their formation described in the available literature. . $^{(5,6)}$

There are two theories that claim to explain the genesis of FBGCs: the proliferative theory and the syncytial theory. The adherents of the first theory believe that multinucleation occurs as a result of direct or indirect division of the nucleus of one cell. Supporters of the second theory are of the opinion that FBGCs arise from the fusion of several mononuclear cells. At the same time, there is also a third opinion, the authors of which consider both ways of their occurrence equally possible.

There are also several points of view regarding the further fate of FBGCs. Most researchers claim that after fulfilling their phagocytic and resorbing functions, FBGCs die. A smaller group of researchers believe that multinucleated cells are stable viable formations capable of long-term differentiation, up to splitting into mononuclear cells, and only a few authors note that multinucleated cells are an accumulation of degenerating cells fused with each other. ${ }^{(7)}$

The purpose of our work was determined by the accumulation of a significant amount of experimental material under the conditions of implantation of a foreign body, a mesh implant, into the region of the anterior abdominal wall in order to obtain experimental inflammation, in which FBGCs were constantly visualized as reactive formations.

This research aimed to study the dynamics of morphological changes in FBGCs under conditions of experimental implantation of a foreign body, a mesh implant, and the possible mechanism of their formation and their state under experimental conditions.

\section{Materials and Methods}

This study was carried out on male Wistar rats, in which a foreign body was implanted - a mesh endoprosthesis made of polypropylene - in the region of the anterior abdominal wall under the aponeurosis of the rectus abdominis muscles.

In vivo experiments were carried out in accordance with the legislation of the Russian Federation, in strict compliance with the European Convention for the protection of animals used for experimental and other purposes (Strasbourg, France, 1986), the provisions of Directive 210/63/EU of the European Parliament and the Council of the European Union of 22 September 2010 on the protection of animals used for scientific purposes (Article 27).

Biomaterial. A section of the anterior abdominal wall with the implanted endoprosthesis was excised on Days 10, 21,30 and 60 after surgery, fixed in $10 \%$ buffered formalin solution. The obtained samples were embedded in paraffin according to standard prescriptions; histological sections with a thickness of 5-7 $\mu \mathrm{m}$ were made and stained with H\&E, according to the methods of Van Gieson and Mallory, and an immunohistochemical study was performed using the marker of cell proliferation (Ki-67).

The revealed structural features of multinucleated cells were recorded by microphotography using a photo attachment and a Levenhuk video camera (USA). The morphometry of multinucleated cells (determination of the FBGC area (S), the numerical density of FBGCs in $1 \mathrm{~mm}^{2}$, the number of nuclei and their diameter (d)) was carried out using an open-source program, Imago J, for image analysis and processing.

Statistical analysis was performed using the Statistica 10.0 software package (Stat-Soft Inc., USA).

\section{Results and Discussion}

During the study, it was revealed that on Day 10 of the experiment, multinucleated cells of relatively small size $\left(\mathrm{S}=1730[1092 ; 3799] \mu \mathrm{m}^{2}\right)$ were seen between the threads of the endoprosthesis and in the immediate vicinity of them, containing about a dozen nuclei in different locations (Fig. 1 [A,B]; Fig. 2 [A, C]). In some cells, large normochromic nuclei with a well-defined, eccentrically located nucleolus and chromatin clumps were seen along the cell periphery (Fig. 2B), leaving the central part of the cytoplasm free; in other cells, large nuclei were in the center and crowded; in the third, the nuclei were displaced to the periphery, to one of the poles of the cell; fourth, they were evenly dispersed throughout the cytoplasm. Also, these nuclei were not the same size: along with very large $(\mathrm{d}=5[4 ; 14] \mu \mathrm{m})$, we saw very small nuclei $(\mathrm{d}$ $=2.5[1 ; 5] \mu \mathrm{m})$ (Fig.1B).

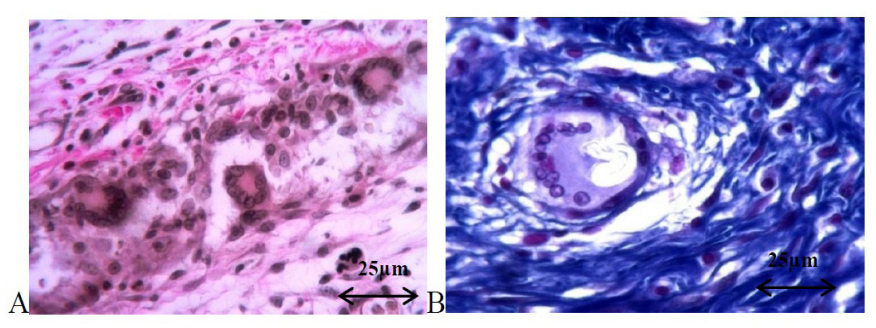

Fig. 1. Micrograph of FBGC on Day 10 after the experiment. $A-\times 200, B-\times 400$. Van Gieson staining (A) and Mallory staining $(B)$.

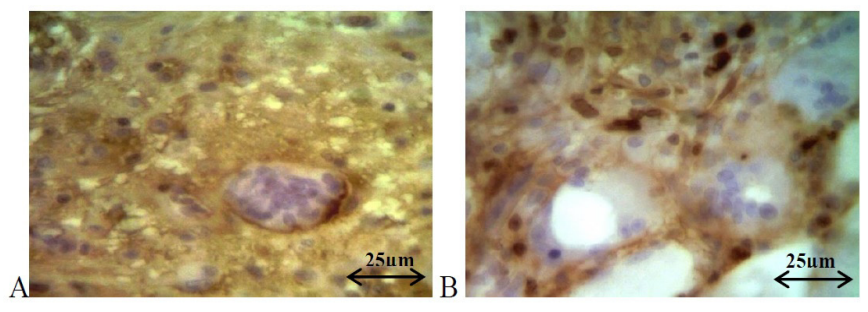

Fig. 2. Micrograph of FBGC on Day 21 after the experiment. Immunohistochemical detection of Ki-67, $\times 400$ 
Most of the nuclei were dense, basophilic, and some were light. Chromatin in the nuclei was dispersed; one or two nucleoli were clearly visible. The cytoplasm of FBGCs was heteromorphic: In some it was oxyphilic; in others it was basophilic and dense; and in a third type, which underwent lysis, the cytoplasm was barely noticeable and weakly colored, and the dark basophilic nuclei of these cells were scattered over the surface of a foreign body (Fig.1B). MNGCs had active phagocytic properties, as evidenced by the presence in their cytoplasm of various captured particles of dead cells.

Three weeks after the beginning of the experiment, around the foreign body (mesh implant threads) the amount of FBGCs increased 1.7 times, against the background of the absence of a significant increase in their dimensional characteristics. The cell cytoplasm was weakly basophilic, often heterogeneous. The darker endoplasm passed to the periphery into a lighter, thinner ectoplasm. The sizes of the nuclei were slightly increased, their diameters varied from $4[2 ; 7] \mu \mathrm{m}$ up to $17[9 ; 40] \mu \mathrm{m}$. The color of the cytoplasm was pale; in some cells, the nuclei were sharply basophilic and rich in chromatin. Many FBGCs have been involved in phagocytosis.

It should be noted that during the immunohistochemical study, none of FBGCs was found to give a positive expression of Ki-67, which may indirectly testify in favor of the syncytial theory of their origin (Fig.2 [A,B]).

On Day 30 of the experiment, the number of multinucleated cells (both small and giant), in comparison with Day 10, significantly increased by 2.1 times, against the background of their constant localization on the threads of the Endoprosthesis (Fig.3 [A,B]). The formation of multinucleated cells continued, as evidenced by the lacing cytoplasm and the splitting of multinucleated cells (Fig.3 [C,D]).
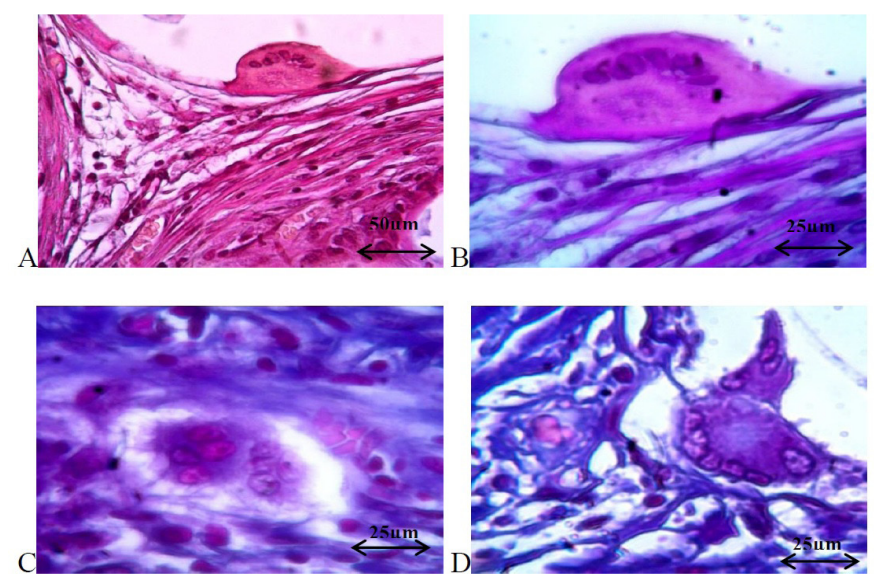

Fig. 3. Micrograph of $F B G C$ on Day 30 after the experiment $(\times 400)$. Van Gieson staining $(A, B)$ and Mallory staining $(C, D)$.

In the cytoplasm of FBGCs, light gaps appeared, which, as it were, separated from the cell areas containing 2-4 nuclei (Fig.3B), which then separated into individual cells. In some areas, we also saw non-viable multinucleated cells subjected to cytolysis.

Two months after the beginning of the experiment, the density and number of FBGCs were increased, in comparison with the previous period, by 1.5 times, and in comparison with Day 10 of the experiment by 2.5 times. Small multinucleated cells $\left(\mathrm{S}=2167.5[895.7 ; 3268.2] \mu \mathrm{m}^{2}\right)$ were located mainly near the threads of the endoprosthesis and their nuclei were small, dark, and located throughout the territory of homogeneously stained cytoplasm (Fig.5A). These cells had a high functional activity, as evidenced by phagocytosed particles visualized in the cytoplasm. At the same time, the process of the FBGC cleavage into smaller multinucleated cells was observed (Fig.4 [A,B]), as evidenced by the presence of light gaps in the cytoplasm, allocating zones containing several nuclei (from 10 to 15 nuclei per cell) (Fig.4B). The splitting of multinucleated cells was also evidenced by the configuration of their bodies, in which grooves corresponding to the outlines of the evolved cells were found (Fig.4A).

Along with their differentiation, multinucleated cells died-lysis and disintegration of the cytoplasm and nuclei were noted. Such disintegrating multinucleated cells were localized at some distance from the threads of the endoprosthesis. In most FBGCs, the enlightened cytoplasm was observed, followed by resorption of the cytoplasm, mainly in its central part (Fig.4 [C,D]). Heterochromic nuclei, pushed to the periphery, underwent lysis and decay.
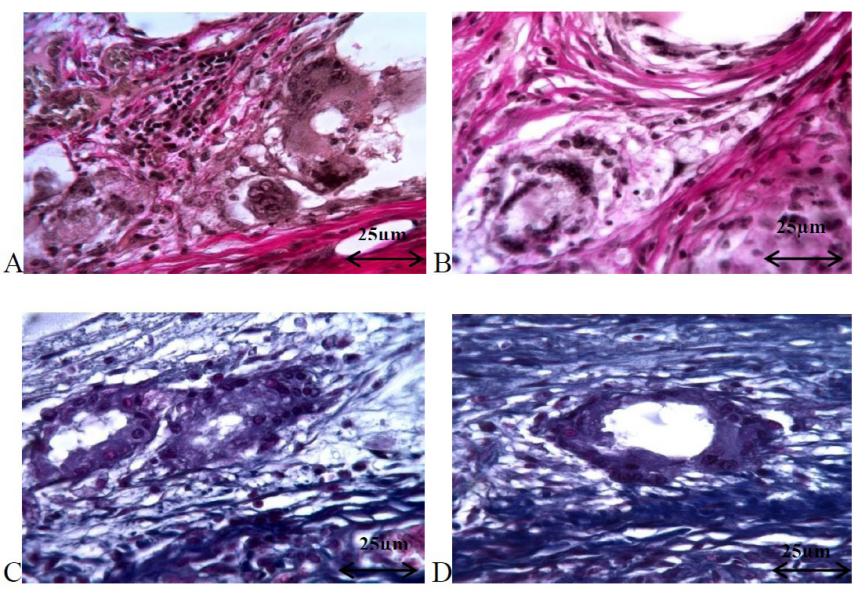

Fig. 4. Micrograph of FBGC on Day 60 after the experiment. $\times 200(A), \times 400(B, C, D)$. Van Gieson staining (A) and Mallory staining $(B, C, D)$.

Summarizing all of the above, the amount, functional activity and morphological diversity of FBGCs gradually increased, reaching a maximum by Day 30 of the experiment. At a later date, some of them died, while the remaining part was differentiated, splitting into small multinucleated cells and mononuclear elements, morphologically identical to macrophages and fibroblasts. The formation of FBGCs continued as long as the mesh implant was in the body.

\section{Conclusion}

Thus, the results of this study and the literature data allow us to draw the following conclusions:

1. The origin of FBGCs can be explained by the syncytial theory, according to which giant multinucleated cells are formed by the fusion of several mononuclear cells. ${ }^{(8,9)}$ 
2. FBGCs are found in a multicellular organism in normal conditions, in the experiment, and in pathology (inflammation).

3. FBGCs are reactive formations that arise in response to various endo- and exogenous irritation.

4. Literary data regarding the potency and further fate of FBGCs indicate two directions: In the first case, FBGCs turn into degenerative formations and die; in the second case, the phenomena of differentiation occur in multinucleated elements, leading to their splitting into mononuclear cells.

\section{Competing Interests} interests.

The authors declare that they have no competing

\section{References}

1. Dolzhikov AA, Kolpakov AYa, Yarosh AL, Molchanova AS, Dolzhikova IN. [Giant foreign body cells and tissue reactions on on the surface of implants]. Kursk scientific and practical bulletin "Man and His health." 2017;(3):86-94. [Article in Russian].

2. Zatolokina MA, Kuznetsov SL, Mutova TV, Mishina ES, Zatolokina ES. [Morphology of multinucleated giant cells in different types of stimulation to reparative regeneration in hernioplasty]. Pathogenesis. 2018;16(4):19-27. doi:
10.25557/2310-0435.2018.04.19-27. [Article in Russian]. 3. Brodbeck WG, Macewan M, Colton E, Meyerson H, Anderson JM. Lymphocytes and the foreign body response: lymphocyte enhancement of macrophage adhesion and fusion. J Biomed Mater Res A. 2005 Aug 1;74(2):222-9. doi: 10.1002/ jbm.a.30313.

4. Brodbeck WG, Anderson JM. Giant cell formation and function. Curr Opin Hematol. 2009 Jan;16(1):53-7. doi: 10.1097/MOH.0b013e32831ac52e.

5. Elchaninov AV, Fatkhudinov TKh., Usman NY, Kananykhina EY, Arutyunyan IV, Makarov AV, Lokhonina AV, Eremina IZ, Surovtsev VV, Goldshtein DV, Bolshakova GB, Glinkina VV, Sukhikh GT. [Dynamics of macrophage populations of the liver after subtotal hepatectomy in rats]. BMC Immunology. 2018;19(1):23. [Article in Russian].

6. Kastellorizios M, Tipnis N, Burgess DJ. Foreign Body Reaction to Subcutaneous Implants. Adv Exp Med Biol. 2015;865:93-108. doi: 10.1007/978-3-319-18603-0 6.

7. Kirk JT, McNally AK, Anderson JM. Polymorphonuclear leukocyte inhibition of monocytes/macrophages in the foreign body reaction. J Biomed Mater Res A. 2010 Sep 1;94(3):6837. doi: $10.1002 / \mathrm{jbm} . \mathrm{a} .32682$.

8. Perdiguero EG, Geissmann F. The development and maintenance of resident macrophages. Nat Immunol. 2016 Jan;17(1):2-8. doi: 10.1038/ni.3341.

9. You Q, Holt M, Yin H, Li G, Hu CJ, Ju C. Role of hepatic resident and infiltrating macrophages in liver repair after acute injury. Biochem Pharmacol. 2013 Sep 15;86(6):836-43. doi: 10.1016/j.bcp.2013.07.006. 